Original Research Paper

\title{
Reprocess of Copper from Worn Printed Circuit Boards
}

\author{
${ }^{1,3}$ Swarnambiga A.K., ${ }^{1,4}$ M. Vidya Kalaivani, ${ }^{1}$ Sarah Sathyawathi and ${ }^{1,2}$ T.S. Ramyaa Lakshmi \\ ${ }^{1}$ Department of Zoology and Biotechnology, Lady Doak College, Madurai- 625002, India \\ ${ }^{2}$ Department of Zoology and Microbiology, Thiagarajar College, Madurai-625009, India \\ ${ }^{3}$ Department of Botany, Bhaurao Kakatkar College, Belagavi-590001, India \\ ${ }^{4}$ Department of Zoology and Biotechnology, Govindammal Aditanar College for Women, Thiruchendur-626215"
}

\author{
Article history \\ Received: 05-01-2019 \\ Revised: 11-01-2019 \\ Accepted: 25-01-2019 \\ Corresponding Author: \\ T.S. Ramyaa Lakshmi \\ Department of Zoology and \\ Microbiology, Thiagarajar \\ College, Madurai- 625009, \\ Tamilnadu, India \\ Email: tsramya@gmail.com
}

\begin{abstract}
The objective of the study is to reuse printed circuit boards which are mainly made of copper. Most top down and bottom up approaches for the synthesis of Copper nanoparticles (CuNPs) needs pure copper (II) sulfate or any other copper salts as a raw material. For the expensive non-ecofriendly reasons, here we used wasted Printed Circuit Boards (PCBs) as an alternative source of copper and Ocimum Sanctum leaf extract was used as a redox agent. Equally distributed, spherically shaped CuNPs around 14.6-19.7nm size were obtained by this process. Further characterization of synthesized nanoparticles was done with UV-Vis spectrophotometer, AFM, FT-IR, SEM and EDAX. Essential physical parameters like $\mathrm{pH}$, Temperature, Reaction Speed were examined for the CuNPs synthesis optimization process. These CuNPs were reused for assessing dye decolorisation promisingly $70 \%$ of dye got decolorized. Based on this study, we conclude that wasted PCBs can be an alternative raw source for CuNPs synthesis and the synthesized nanoparticles can be used for environmental pollution control.
\end{abstract}

\section{Keywords: Copper, E-Waste, Leaf Extract, Nanoparticles, Bioleaching}

\section{Introduction}

Electronic waste popularly known as 'E-waste' broadly comprises of Waste from Electrical and Electronic Equipment (WEEE). E-waste is being generated two to three times faster than other waste streams like solid municipal wastes, hazardous wastes etc., (Grossman, 2010). Recycling of E-waste is one of the important processes which involve the conversion of used electronic devices to usable raw materials. Every year, millions of tons of E-waste get distributed from countries like U.S and Australia to developing countries like India and China, where it is dumped at landfills, which can cause pollution to the environment owing to their toxic nature (Baldé et al., 2015). Printed Circuit Boards (PCBs) represent 3\% of the mass of global WEEE generated (Dalrymple et al., 2007). Waste PCB contains nearly $28 \%$ metals and the purity of metals is more than 10 times higher than that of rich-content minerals (Li et al., 2007). Due to significant risks to human health and the environment, recovering waste PCBs has now become increasingly important, which is mostly carried out in poor working conditions using crude technologies. Serious pollution has been generated in the recovering process such as exposure to polybrominateddiphenyl ethers, dibenzofurans and polychlorinated dibenzo-dioxins (Duan et al., 2011). With so many physical and chemical methods are available for recovering waste PCBs, precious metals were lost by both these recovering processes ( $\mathrm{Li}$ and $\mathrm{Xu}$, 2010; Ruan et al., 2013). Therefore, environmentfriendly technology is immediately required for improving the additional value of waste PCBs recovery. On the other hand, copper nanoparticles have gained unique physical and chemical properties and synthesis of CuNPs is less expensive and has created great interest in medical research recently. Copper nanoparticles have shown wide applications in the field of medical and industrial use such as gas sensors, catalytic processes, solar cells etc., (Li et al., 2007). At the present time biological approaches using microorganisms and plant extracts for the synthesis of metal nanoparticles have been recommended as appreciated replacement to traditional synthetic methods (Krumov et al., 2009; Mishra and Rhee, 2010; Zare et al., 2017). 
The aim of the present study is to lay on bioleaching as an ecologically safe process to remove heavy metals from e-waste, and to synthesize copper nanoparticles from worn out mobile phone printed circuit boards using the plant extract Ocimum sanctum (Tulsi). Additionally, the study focuses on the characterization of the nanoparticles and the dye discoloration activity of synthesized copper nanoparticles.

\section{About the Plant}

Ocimum sanctum (Tulsi) is considered as Holy basil in India. It is a traditional medicinal plant and belongs to the family Lamiaceae. Ocimum sanctum remains as an active area of research, and recent innovation on Ocimum sanctum has reported the inhibitory activity against HIV-1 reverse transcriptase (Anuya et al., 2010) also it has been widely acknowledged for the treatment of headaches, coughs, diarrhea, constipation, warts, worms, kidney malfunctions etc., (Simon et al., 1999). Recently $O$. sanctum leaf extracts (Fig. 1) have been used in the synthesis of different nanoparticles like iron oxide, silver (Mallikarjunaa et al., 2011; Singhal et al., 2011), platinum (Soundarrajan et al., 2012) and gold from readily available chemicals. But to the best of our knowledge, the use of Ocimum sanctum leaf extract for the biosynthesis of copper nanoparticles using e-waste has not yet been reported. Hence, the present study is dealt with the biosynthesis of copper nanoparticles using Ocimum sanctum leaf extract from worn Printed Circuit Boards (PCB).

\section{Materials and Methods}

\section{Printed Circuit Boards (PCB) Collection and Copper Content Analysis}

A modified protocol of Sheng and Estell (2007) was followed for PCB collections where in discarded mobile phone circuit boards were collected from mobile phone service centers. The mobile phone circuit board was cut into pieces and ground to a minute powder using the mechanical grinder. The PCB powder was sieved, autoclaved and used for further experiments (Fig. 2a and $b$ ). About $100 \mathrm{~mL}$ of aqua regia was added to $1 \mathrm{~g}$ of PCB powder and refluxed in a round bottomed flask at $100^{\circ} \mathrm{C}$ for 1 hour using heating mantle. The solution was cooled and the volume was made up to $100 \mathrm{~mL}$ using distilled water. The solution was filtered and stored at $4{ }^{\circ} \mathrm{C}$ for further analysis.

\section{Preparation of Ocimum sanctum Extract}

About $10 \mathrm{~g}$ of fresh Ocimum sanctum leaves was surface sterilized, finely chopped and mixed with $50 \mathrm{~mL}$ of distilled water. The mixture was stirred at $60^{\circ} \mathrm{C}$ for 1 hour, cooled and then filtered through a $0.45 \mu \mathrm{m}$ membrane filter and stored at $4^{\circ} \mathrm{C}$ for further experiments.

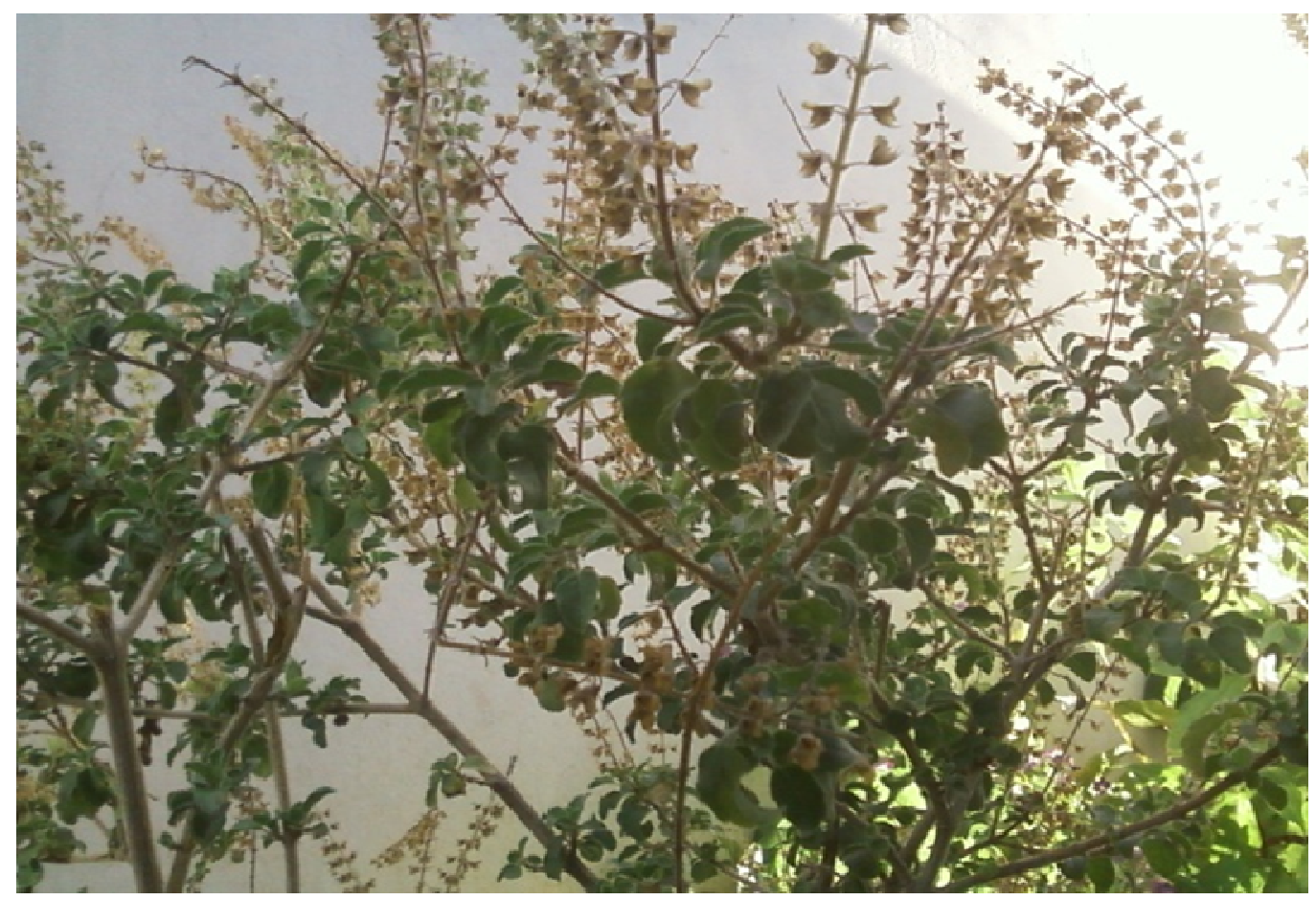

Fig. 1: Ocimum sanctum plant 


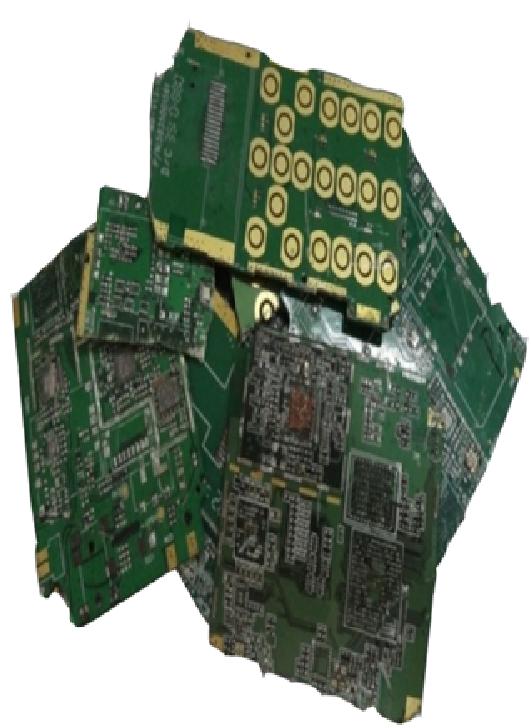

(a)

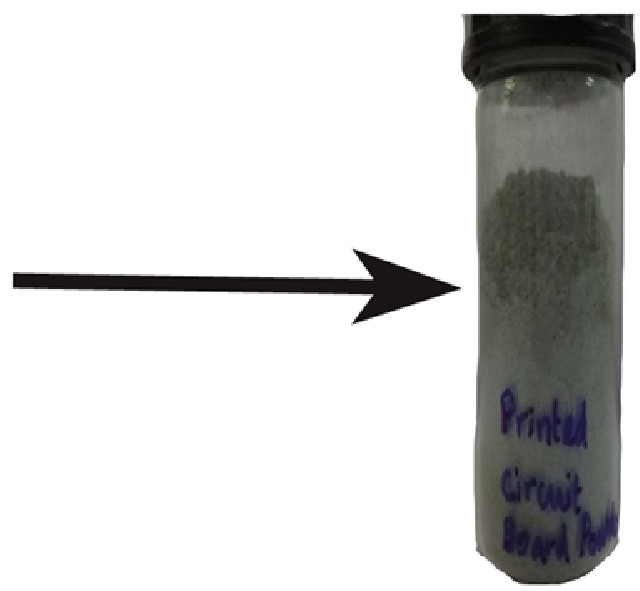

(b)

Fig. 2: (a) Mobile phone PCBs (b) Powdered PCBs

\section{Bioleaching Process}

In the bioleaching process $1 \mathrm{~g}$ of autoclaved Printed Circuit Board (PCB) powder and $1 \mathrm{~mL}$ of $O$. sanctum extract was added to the flask containing $99 \mathrm{~mL}$ of sterile distilled water and incubated in an incubator shaker at $37^{\circ} \mathrm{C}$ for visible color change. The bioleaching of copper ions was monitored by periodic sampling of aliquots of the suspension and measured using UV-Vis spectroscopy.

\section{Characterization of the Synthesized Copper Nanoparticles}

Optical absorption measurements of nanoparticles have been carried out by SPECORD 210 PLUS UV-Vis spectrophotometer. The morphology of the synthesized nanoparticles was studied using Atomic Force Microscope (NANOSURF EASY SCAN 2) and Scanning Electron Microscope (SEM- EDAX FEI QUANTA 200). The FT-IR (NICOLET 380), analysis have been used to receive information about the element to element bounding or possible functional groups attached to the nanoparticles that are responsible for capping and efficient stabilization of the synthesized copper nanoparticles. The elemental analysis or the chemical characterization of the synthesized nanoparticles was determined by Energy-dispersive X-ray spectroscopy.

\section{Effect of Physical Parameters on the Synthesis of Copper Nanoparticles}

The essential factors like solution $\mathrm{pH}$, temperature, reaction mixing speed, concentration of the extracts used etc., are the altering factors for nanoparticles synthesis. Meager changes in the above mentioned parameters will affect the nanoparticle size, shape and synthesis. In our study, we have taken three important parameters $(\mathrm{pH}$, Temperature, Reaction Speed) for the optimization process. Different mixing speed range from $100 \mathrm{rpm}$ to $1000 \mathrm{rpm}$, reaction mixture $\mathrm{pH}$ ranging from $\mathrm{pH} 2$ to $\mathrm{pH}$ 12 and reaction temperatures ranging from $40^{\circ} \mathrm{C}$ to $100^{\circ} \mathrm{C}$ were examined to observe the optimum conditions for CuNPs synthesis. All experiments were performed in triplicates and for each parameter, respective controls were maintained.

\section{Dye Discoloration Activity of Synthesized Copper Nanoparticles}

The discoloration of Methyl Orange (MO) in the absence and presence of CuNPs was studied spectrotometrically by using SPECORD 210 PLUS UVVis spectrophotometer determining the decrease in the absorbance at $464 \mathrm{~nm}$. To a mixture containing $300 \mu \mathrm{L}$ of MO $(30 \mu \mathrm{g}) 1 \mathrm{~mL}$ of CuNPs containing $50 \mu \mathrm{g}$ was added and made up to $3 \mathrm{~mL}$ with distilled water. The 5 discoloration reaction was studied spectrophotometrically at room temperature after two to three hours.

\section{Results and Discussion}

\section{Determination of Copper in Mobile Phone Printed Circuit Board (PCB)}

PCBs from personal computers and mobile phones contain the highest amounts of valuable metals (Cui and Zhang, 2008). Previous studies reported that the amount of copper present in the PCBs ranges from $12 \%$ to $35 \%$ which were determined by Atomic Absorption Spectroscopy (AAS) (Chehade et al., 2012; Willner et al., 2013). This difference in the concentration of copper may 
also be attributed to the analytical methods (Pradhan and Kumar, 2012). In the present study chemical analysis of ground powder of mobile phone printed circuit boards was carried out to determine the concentration of copper present in it. $76.6 \%$ of Copper was present in the ground powder of mobile phone printed circuit board which was also confirmed by AAS. Based on the previous findings, mineral content and recovery percentage varies based on the types of PCBs that we use for our studies (Xiang et al., 2010; Gu et al., 2017). In our study, we have got 76.6 \pm 9.5 of copper from $\mathrm{mg} / \mathrm{g}$ PCBs and recovered $68.6 \%$ copper with $O$. Sanctum leaf extract bioleaching process that was conformed with the help of AAS.

\section{Synthesis of Copper Nanoparticles from Mobile Phone Printed Circuit Board}

\section{Visual Inspection}

The synthesis of nanoparticles is preliminarily confirmed by the visual color change due to the excitation of the surface plasmon resonance. Subhankari and Nayak (2013) reported that the synthesis of copper nano particles by the aqueous extract of Syzygiumaro maticum is indicated by the color change from dark brown to sea green after the addition of copper sulphate solution to the aqueous extract. A similar color change has been reported by other workers by the addition of 5 $\mathrm{mm}$ copper sulphate solution to the Morganella sp. culture led to the appearance of a dark green color solution indicating the formation of nanoparticles (Ramanathan et al., 2013). Electroplating industry wastewater when treated with Pseudomonas stutzeri biomass turned red due to the surface Plasmon resonance of the copper nanoparticles formed (Varshney et al.,
2011). In the same way the visual color change was observed from the aqueous extract of Ocimum sanctum showed the color variation from yellow to brown after the addition of PCB (Fig $3 a$ and $b$ ). The formation of copper nanoparticles is primarily confirmed by the visible color change from yellow to brown.

\section{Characterization of Synthesized Nanoparticles}

\section{$U V-V i s$ Spectroscopy}

Next level of confirmation was determined by UVVis spectroscopy, it is used to study the size and shape of nanoparticles, the plasmon peak positions and shapes are sensitive to particle size in aqueous suspensions. The absorption peaks arise from the localized Surface Plasmon Resonance (SPR), which is predicted by the well-known resonance condition. The exact position of the SPR band may shift depending on the individual particle properties including shape, size, and capping agents (Galkowski et al., 2007). The UV-Vis spectra of reaction solution containing the PCB waste treated with aqueous extract of Ocimum sanctum shows the broad peak from $350-450 \mathrm{~nm}$ with the $\lambda \max$ at $390 \mathrm{~nm}$ as indicated in Fig. 4. A red shift in the wavelength from 325 to $450 \mathrm{~nm}$ was observed with the increase in amount of precursor. The shift is due to the generation of greater amount $\mathrm{Cu}_{2}^{+}$ions, which increases the nucleation rate and also indicates the generation of smaller nanoparticle in the solution. Based on our work, UV- plasmon peak was seen around wave length of $390 \mathrm{~nm}$, which indicates the presence of small separate CuNPs average particle size less than $20 \mathrm{~nm}$. This results specifies the high concentration of capping agents and then smaller CuNPs (Xiong et al., 2011).

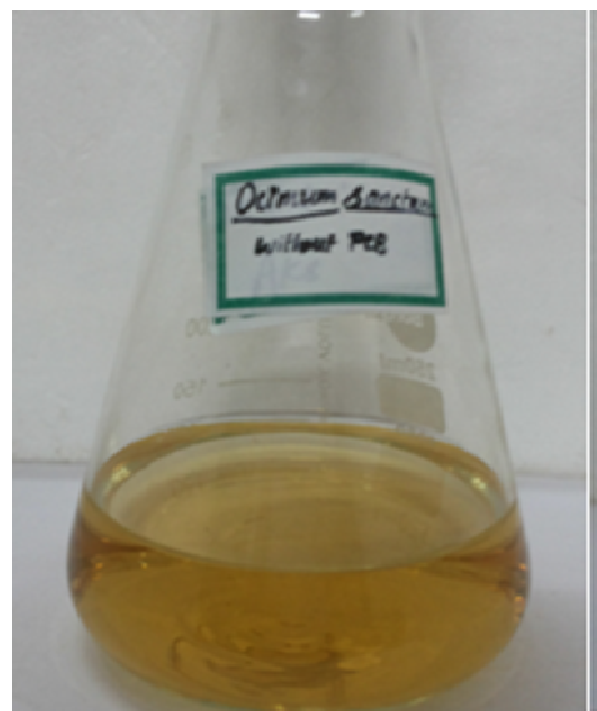

(a)

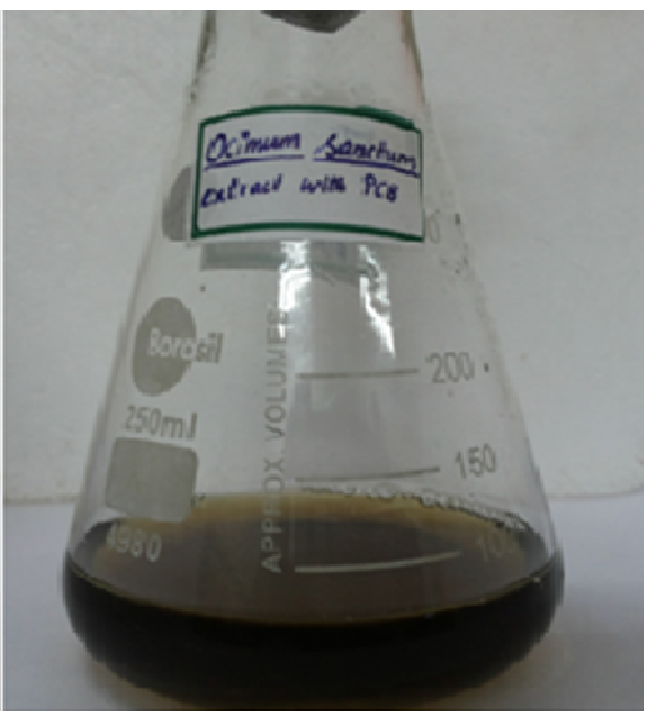

(b)

Fig. 3: Aqueous extract of Ocimum sanctum without Printed Circuit Board (PCB) waste (b) Aqueous extract of Ocimum sanctum after incubation for $24 \mathrm{~h}$ with PCB waste 


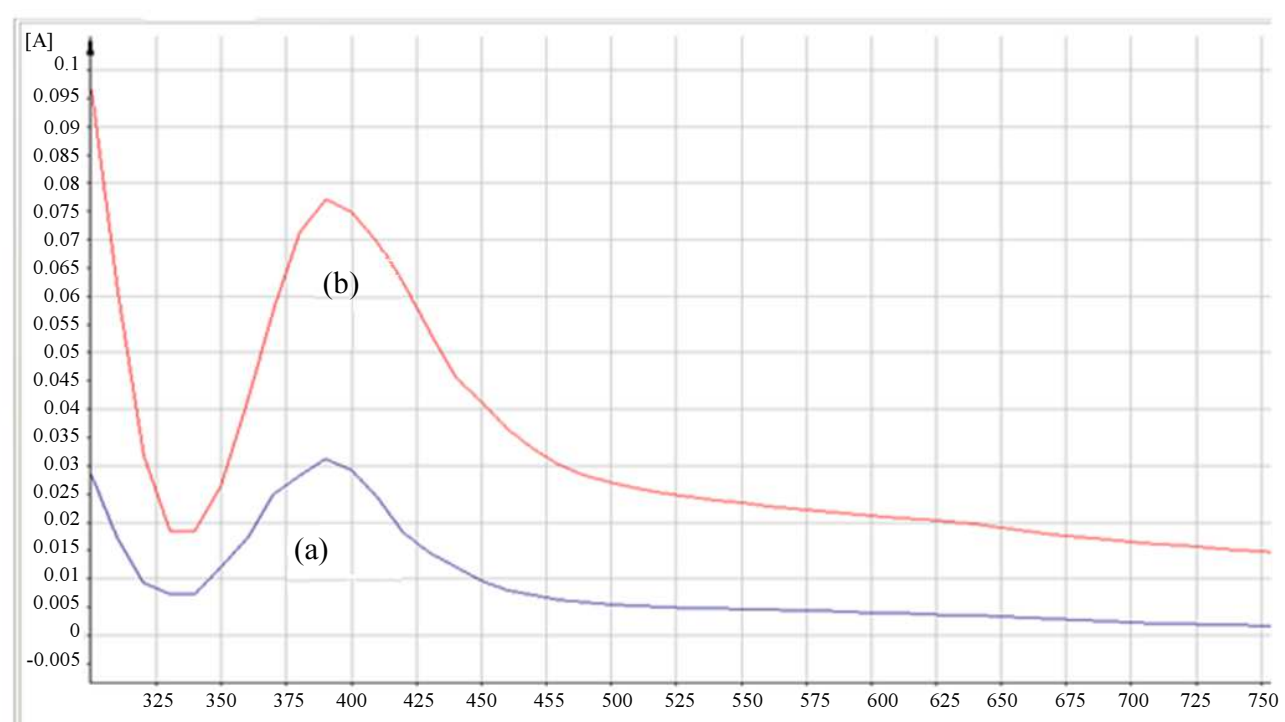

Fig. 4: UV-Vis spectrum of aqueous extract of $O$. sanctum (a) Aqueous extract incubated with Printed Circuit Board waste (b) Aqueous extract incubated with standard Copper solution

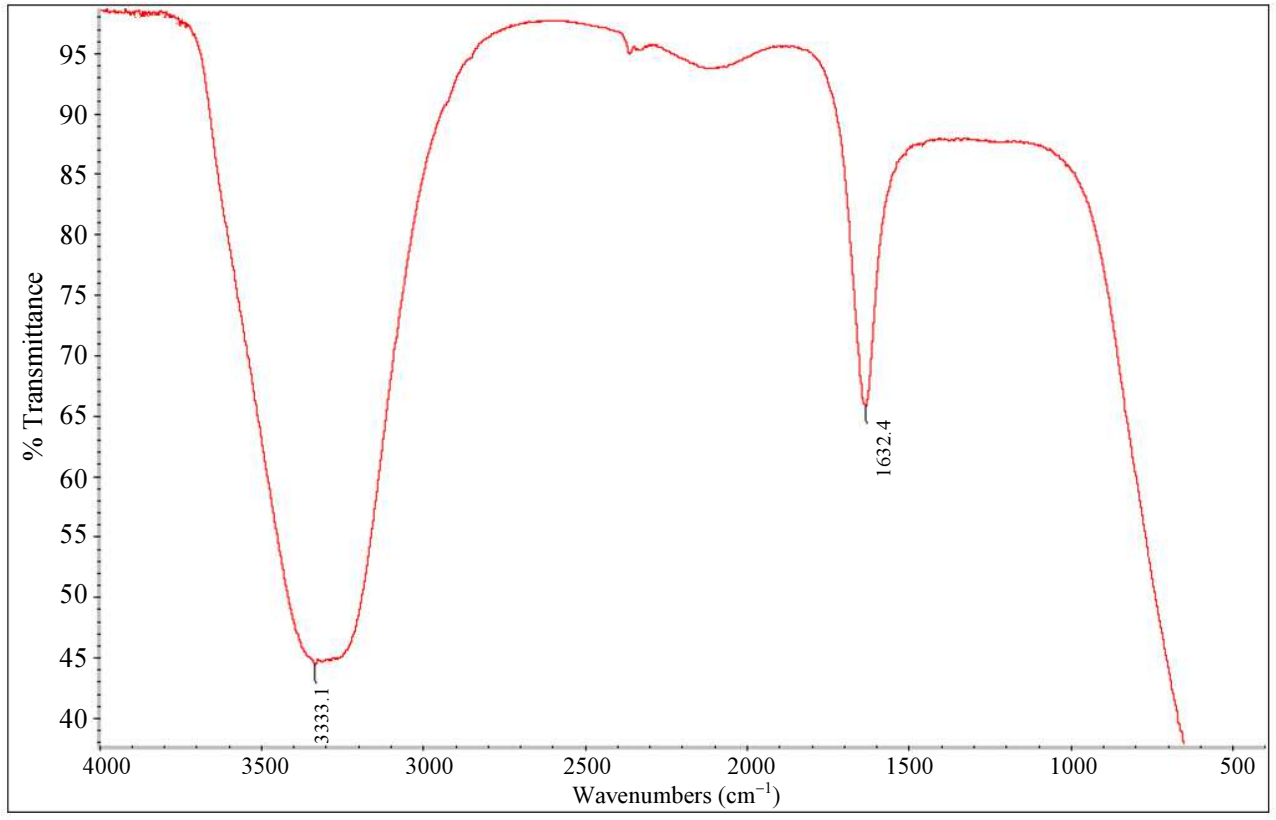

Fig. 5: FT-IR spectrum of copper nanoparticles synthesised using $O$. sanctum aqueous extract

\section{Fourier Transform Infrared Spectroscopy}

FT-IR spectroscopy is conducted to identify the possible interactions between reducing agents and the functional groups present on nanoparticles. The size of peak in the spectrum is directionally proportional to the number of functional groups that present in the nanomaterial (Chauhan et al., 2012). Peaks were located at about 1632.4 and $3333.6 \mathrm{~cm}^{-1}$ for copper nanoparticles synthesized from $O$. sanctum (Fig. 5). The peak at 1634.7 characterize the bending vibrations of $\mathrm{O}-\mathrm{H}$ bonds in $\mathrm{OH}$ groups and the peak at 3333.6 characterize the stretching vibrations of $\mathrm{O}-\mathrm{H}$ bonds in $\mathrm{H}_{2} \mathrm{O}$ molecules. Similar peaks have been reported by (Petrov et al., 2012; Majumder, 2013) for copper nanoparticles. The peaks 1634.7 is close to that reported for native proteins (Macdonald and Smith, 1996) which suggests that proteins are interacting with synthesized nanoparticles 
and also their secondary structure were not affected during reaction with copper ions or after binding with copper nanoparticles (Fayaz et al., 2010).

\section{Atomic Force Microscopy}

Atomic Force Microscopy (AFM) is primarily technique for studying the shape, size 2, 3- Dimensional views and height distribution of nanoparticles. Previous finding explain that the copper oxide nanoparticle have a notable propensity to form uniform size and shaped 7 agglomerates at less concentration because they are very stable molecules, air and water and did not convert nanoparticles into any other associated compounds (Fan et al., 2003). Honary et al. (2012; Sampath et al., 2014) also studied the synthesis of copper nanoparticles by Penicillium spp., wherein green chemical reduction method was followed and observed spherical, Jasmin bud-like copper nanoparticles respectively. Ansilin et al. (2016) reported that the size of CuNPs are found in different sizes range between 49-324 nm using Azadirachta indica (neem) leaf aqueous extract. In our study, Fig. 6 displays the three dimensional AFM image of synthesized copper nanoparticles by PCB waste using $O$. sanctum leaf extract. Most of the copper oxide nanoparticles were found to be spherical in shape with smooth surface and compact structure. Based on the observation, current study results imply that the synthesized CuNPs are equally distributed with spherical in shape.

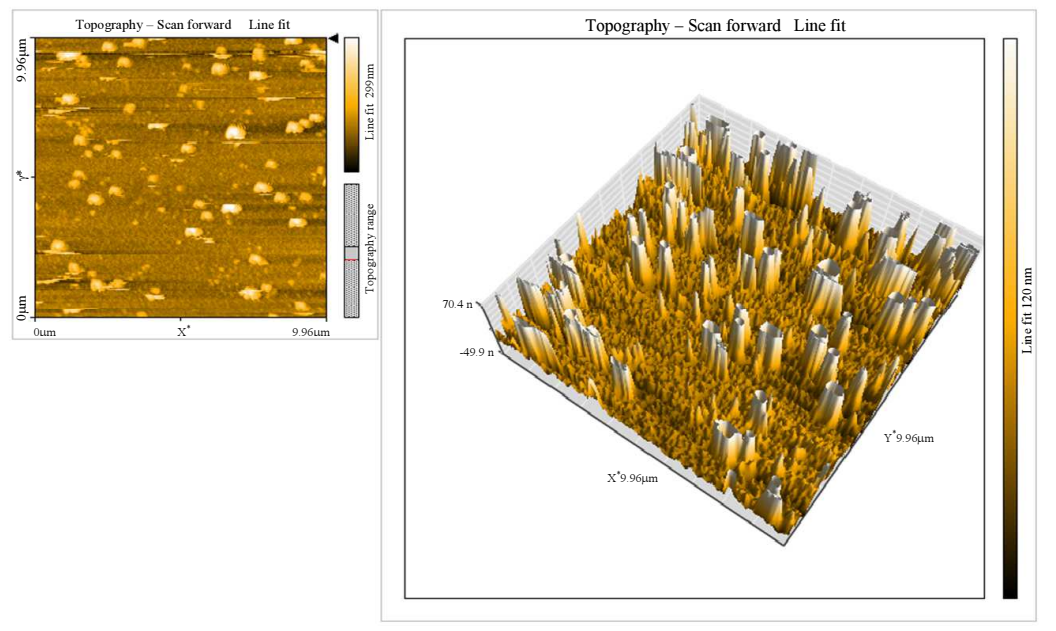

Fig. 6: AFM image of copper nanoparticles synthesised from $\mathrm{PCB}$ waste using $O$. sanctum

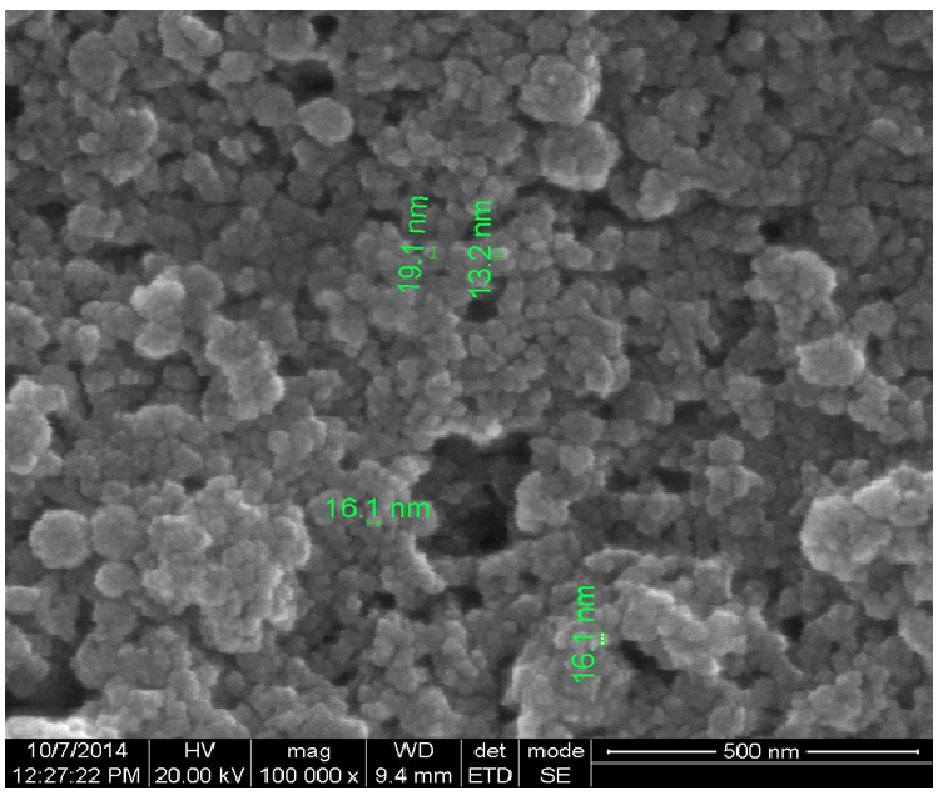

Fig. 7: Scanning electron microscopic image of synthesized copper nonparticles 


\section{Scanning Electron Microscopy and Energy Dispersive Spectroscopy (SEM-EDAX) Analysis}

SEM is another visualizing technique used to observe the morphology of synthesized biomolecules. SEM produce 2D images based on two electron scattering (Gupta and Kant, 2013). Figure 7 illustration the copper nanoparticles synthesized by the plant extract $O$. sanctum. Copper nanoparticles found to be spherical and relatively uniform shape of the copper nanoparticles was confirmed in the range of $14.6-19.7 \mathrm{~nm}$. The average particle size of the $\mathrm{Cu}$ nanoparticles is around $17 \mathrm{~nm}$. Energy Dispersive Analysis of X-Rays (EDAX) provides data on the surface atomic distribution and chemical composition of the synthesized product. EDAX analysis of the synthesized product from PCB waste using $O$. sanctum shows elemental signals of copper at 1.00, 8.00 and $9.00 \mathrm{keV}$ (Fig. 8). Synthesized CuNPs showed strong copper signals in the EDAX image along with $\mathrm{P}$ and $\mathrm{C}$ peaks, which may indicates the biomolecules that were attach to the surface of CuNPs (Chung et al., 2017).

\section{Effect of pH on Copper Nanoparticle Synthesis}

Copper reduction reaction depends on the various factors like aqueous media $\mathrm{pH}$, Particle size, shape, type of solvent etc., (Zhang et al., 2009) (Fig. 9) shows the UV-vis absorption spectra of effect of $\mathrm{pH}$ on nanoparticle formation for the $\mathrm{pH}$ ranging from 2 to 12 . In which Plasmon resonance was not clearly visible at $\mathrm{pH} 2$. Different peak values were observed at $382,380,379$ and $378 \mathrm{~nm}$ for $\mathrm{pH} 2$ to 12 . Synthesis of copper nanoparticles using Ocimum sanctum extract was pragmatic only after $\mathrm{pH} 4$ with the peak at $382 \mathrm{~nm}$.

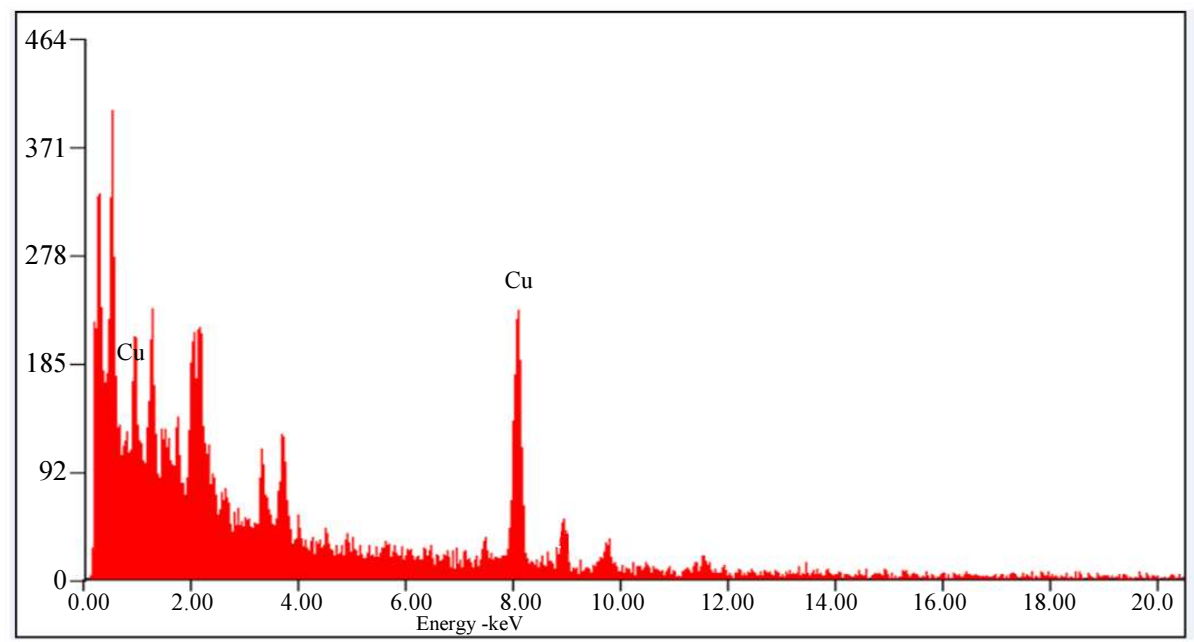

Fig. 8: EDAX spectrum of nonparticles synthesised form PCB waste using O. anctum aqueous extract

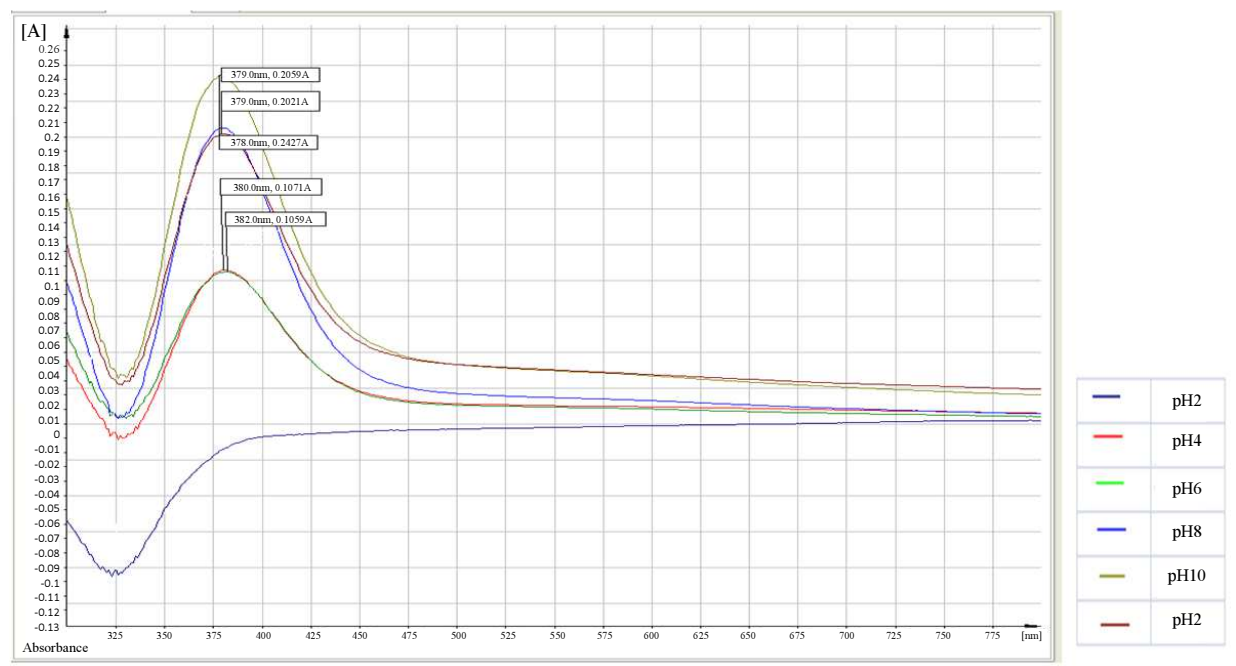

Fig. 9: UV-Vis spectra showing the effect of $\mathrm{pH}$ on the synthesised of copper nonparticles form PCB waste using aqueous extract of O. anctum 


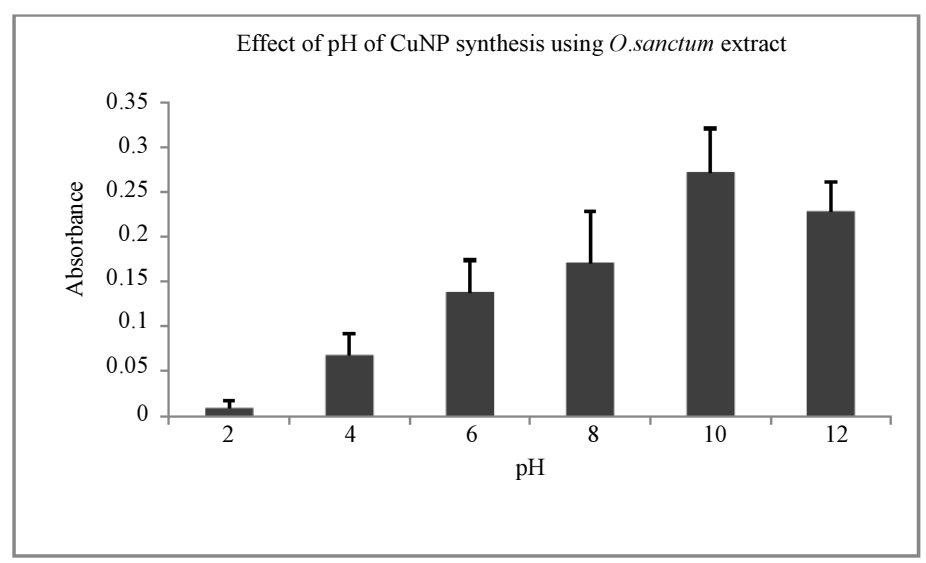

Fig. 10: Effect of $\mathrm{pH}$ on the synthesised of copper nonparticles form PCB waste using aqueous extract of $O$. anctum

While increasing the $\mathrm{pH}$ there was increase in nanoparticle synthesis up to $\mathrm{pH} 10$. At $\mathrm{pH} 12$, the intensity of peak decreased around the maximum $\mathrm{pH}$ indicating the decrease in particle synthesis. According to the literature, the alkali concentration and the $\mathrm{pH}$ value should play a vital role in controlling the size distribution of finally synthesized nanoparticles (Ji et al., 2007) (Fig. 10) represents the graphical representation of mean absorbance of triplicates measured with different $\mathrm{pH}$ range.

\section{Effect of Temperature}

The variations in the reaction temperature will unquestionably influence the morphology and structure of nanomaterials. In this cause, temperature of a solution is a major dependable factor. The processes nanoparticles synthesis needs to lower their Gibbs free energy for their nucleation and the growth of particles formation events. This can be achieved with the help of diluting or reducing solution supersaturation because absolutely a high supersaturated solution has high Gibbs free energy (Gaber et al., 2014). For nanoparticle synthesis by physical methods need more or less than $350^{\circ} \mathrm{C}$ but green synthesis or natural methods requires less than $100^{\circ} \mathrm{C}$ (Patra and Baek, 2014). A range between 40 to $100^{\circ} \mathrm{C}$ temperatures were used for copper nanoparticles synthesis using $O$. sanctum leaf extract. Figure 11 indicates that increasing reaction temperature induces the production of copper nanoparticle synthesis by this method. Up to $80^{\circ} \mathrm{C}$ the production rate shows gradual increase after that it shows a decline state. Generally, for Gibbs free energy change, low supersaturation, nucleation and high growth rates are the responsible factors for green nanoparticle synthesis. This was obtained in this method at $80^{\circ} \mathrm{C}$, which means that the optimum temperature for copper nanoparticle synthesis by this method is less than $90^{\circ} \mathrm{C}$.

\section{Effect of Speed}

Increasing the reaction speed leads to the more energy release and rapid monomodal dispersion of nanoparticles occur in the polymeric organic phase. Copper nanoparticle prepared at lower homogenization speeds $(100,250,500$, $750,1000 \mathrm{rpm})$ resulted in less absorbance Fig. 12 demonstrate that the gradual increase in reaction speed will be an inducing factor for green particles synthesis process. A recent study results reported that the encapsulation efficiency increased when the speed of emulsification was increased from $800 \mathrm{rpm}$ to10, $000 \mathrm{rpm}$ respectively. Due to the high degree of agitation, anomalous diffusion of particles can be a reducing factor for nanoparticle production (Sharma et al., 2016). In our study we observed the nanoparticle production rate alone. Based on our results $750-1000 \mathrm{rpm}$ can be an optimum reaction speed for green nanoparticle synthesis process.

\section{Dye Discoloration Activity of the Synthesized Copper Nanoparticles}

In the dye discoloration activity, the color of the reaction mixture started to fade immediately after an hour indicating the degradation of methyl orange (Fig. 13). After $24 \mathrm{~h}, 68.4 \%$ of the dye have been decolorized by the copper nanoparticles synthesized by aqueous extract of $O$. sanctum. The absorption of the visible band in UVSpec at $464 \mathrm{~nm}$ decreased rapidly, which indications the aromatic fragment degradation in the dye molecule and its intermediates (Ince and Tezcanli, 2001) and reflects the discoloration effects of the synthesized nanoparticles (Li et al., 2015). Green synthesized CuNPs can act as catalyst and leaves extract has no role in the degradation of MO (Devi and Singh, 2014). It was thus observed that copper nanoparticles synthesized by using natural, renewable and eco-friendly, reducing agents exhibit discoloration activity against dye molecules and can be used in dye effluent treatment. 


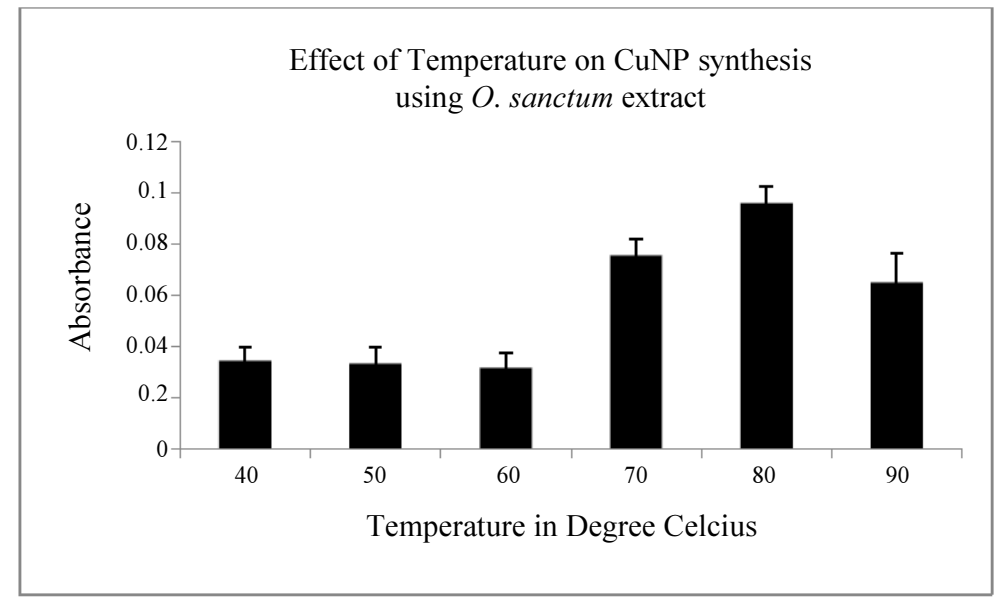

Fig. 11: Effect of temperature on the synthesise of copper nonparticles form PCB waste using aqueous extract of $O$. anctum (Values represent average of triplicates; bars indicate standard error)

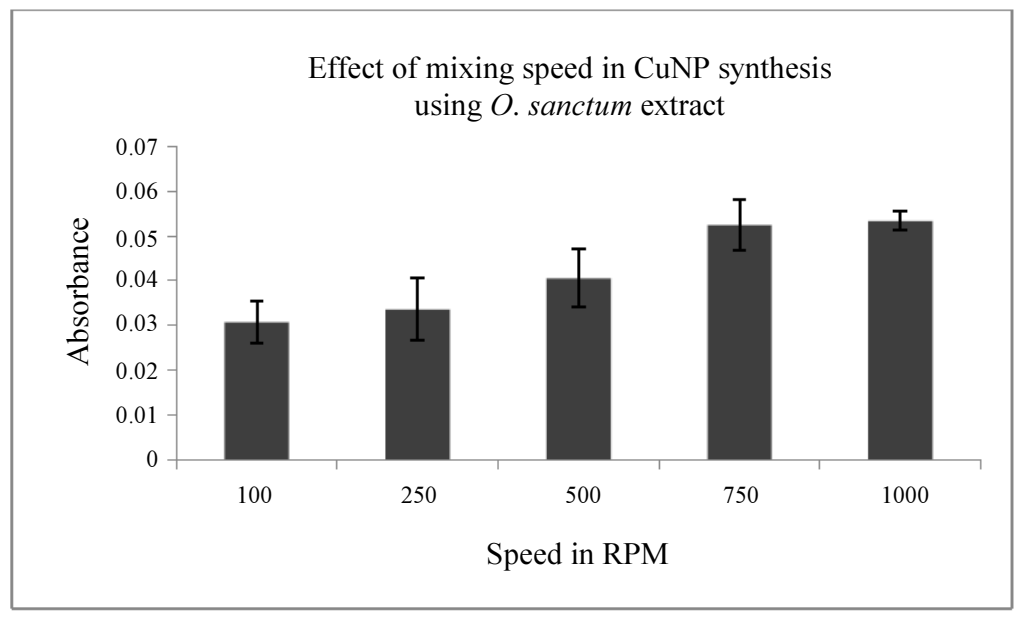

Fig. 12: Effect of reaction mixing speed on the synthesise of copper nonparticles form PCB waste using aqueous extract of $O$. anctum (Values represent average of triplicates; bars indicate standard error)

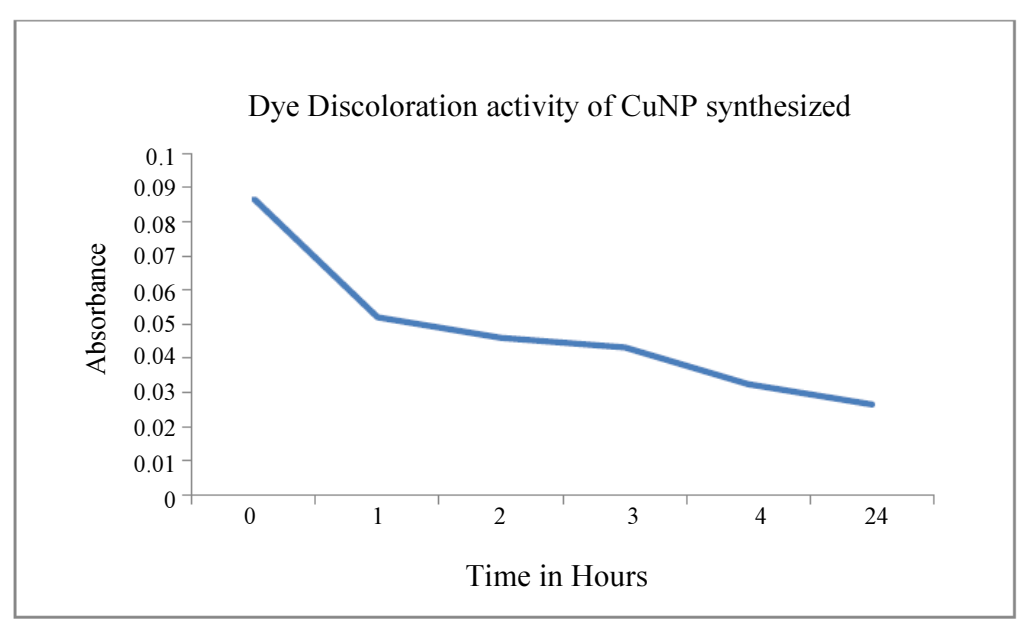

Fig. 13: Dye discoloration activity of CuNP 


\section{Conclusion}

From these results we conclude that, by using EWaste and green chemistry, the copper nanoparticles have been prepared using Ocimum Sanctum leaf extract. The synthesized copper nanoparticles was able to decolorize synthetic dyes. Our preliminary results suggest that copper nanoparticles can be an alternative economical source for industrial effluent treatments. Due to its good stability, copper nanoparticles could also be effectively used in various other fields like drug delivery, antimicrobials, wound healing as well as on industrial applications. Thus, we conclude that this protocol could be used in other heavy metal bioleaching process. Since it is cost effective and ecofriendly approach for the recovery of valuable metals and an alternative to the chemical synthesis protocol.

\section{Acknowledgement}

We greatly acknowledge the host institutions for providing us the space and basic chemicals.

\section{Author's Contributions}

All authors contributed equally in thepreparation and development of thismanuscript

\section{Conflict of Interest}

The authors declare that they have no conflict of interest.

\section{References}

Ansilin, S., J.K. Nair, C. Aswathy, V. Rama and J. Peter et al., 2016. Green synthesis and characterisation of copper oxide nanoparticles using Azadirachta indica (neem) leaf aqueous extract. J. Nanoscience Technol., 221-223.

Anuya, A.R., Y.A. Ramkrishna and A.D. Ranjana, 2010. In-vitro testing of anti-HIV activity of some medicinal plants. Indian J. Natural Products Resources, 1: 193-199.

Baldé, C.P., F. Wang, R. Kuehr and J. Huisman, 2015. The global e-waste monitor - 2014, United Nations University, IAS - SCYCLE, Bonn, Germany.

Chauhan, R.P., C. Gupta and D. Prakash, 2012. Methodological advancements in green nanotechnology and their applications in biological synthesis of herbal nanoparticles. Int. J. Bioassays, 1: 6-10.

Chehade, Y., A. Siddique, H. Alayan, N. Sadasivam and S. Nusri et al., 2012. Recovery of Gold, Silver, Palladium, and Copper from Waste Printed Circuit Boards. ICCEE, Dubai.
Chung, I.M., A. Abdul Rahuman, S. Marimuthu, A. Vishnu Kirthi and K. Anbarasan et al., 2017. Green synthesis of copper nanoparticles using Eclipta prostrata leaves extract and their antioxidant and cytotoxic activities. Experimental Therapeutic Medicine, 14: 18-24.

Cui, J. and L. Zhang, 2008. Metallurgical recovery of metals from electronic waste: A review. J. Hazardous Materials, 158: 228-256. DOI: $10.1016 /$ j.jhazmat.2008.02.001

Dalrymple, I., N. Wright, R. Kellner, N. Bains and K. Geraghty et al., 2007. An integrated approach to electronic waste (WEEE) recycling. Circuit World, 33: 52-58. DOI: 10.1108/03056120710750256

Devi, H.S. and T.D. Singh, 2014. Synthesis of copper oxide nanoparticles by a novel method and its application in the degradation of methyl orange. Advance Electronic Electric Eng., 4: 83-88.

Duan, H., J. Li, Y. Liu, N. Yamazaki and W. Jiang, 2011. Characterization and inventory of $\mathrm{PCDD} / \mathrm{Fs}$ and $\mathrm{PBDD} / \mathrm{Fs}$ emissions from the incineration of waste printed circuit board. Environ. Sci. Technol., 45: 6322-6328. DOI: 10.1021/es2007403

Fan, H., L. Yang, W. Hua, X. Wu and Z. Wu et al., 2003. Controlled synthesis of monodispersed $\mathrm{CuO}$ nanocrystals. Nanotechnology, 15: 37. DOI: $10.1088 / 0957-4484 / 15 / 1 / 007$

Fayaz, A.M., K. Balaji, M. Girilal, R. Yadav and P.T. Kalaichelvan et al., 2010. Biogenic synthesis of silver nanoparticles and their synergistic effect with antibiotics: A study against gram-positive and gramnegative bacteria. Nanomedicine: Nanotech., Biology Medicine, 6: 103-109. DOI: 10.1016/j.nano.2009.04.006

Gaber, A., M.A. Abdel-Rahim, A.Y. Abdel-Latief and M.N. Abdel-Salam, 2014. Influence of calcination temperature on the structure and porosity of nanocrystalline $\mathrm{SnO}_{2}$ synthesized by a conventional precipitation method. Int. J. Electrochem. Sci., 9: 81-95.

Galkowski, M.T., H. Bala, B. Grzybowska and P.J. Kulesza, 2007. Evaluation of polyaniline films containing traces of dispersed platinum for protection of stainless steel against corrosion. Electrochimica Acta, 44: 2157-2163.

Grossman, E., 2010. High Tech Trash: Digital Devices, Hidden Toxics and Human Health, 1st Edn., Island Press, ISBN-10: 1597263834, pp: 352.

Gu, W., J. Bai, B. Dong, X. Zhuang and J. Zhao et al., 2017. Enhanced bioleaching efficiency of copper from waste printed circuit board driven by nitrogendoped carbon nanotubes modified electrode. Chemical Eng. J., 324: 122-129.

DOI: $10.1016 /$ j.cej.2017.05.024 
Gupta, A.R. and V. Kant, 2013. Synthesis, characterization and biomedical applications of nanoparticles. Sci. Int., 1: 167-174.

DOI: $10.5567 /$ sciintl.2013.167.174

Honary, S., H. Barabadi, E. Gharaei-Fathabad and F. Naghib, 2012. Green synthesis of copper oxide nanoparticles using Penicillium aurantiogriseum, Penicillium citrinum and Penicillium waksmanii. Dig. J. Nanomater Bios., 7: 999-1005.

Ince, N.H. and G. Tezcanli, 2001. Reactive dyestuff degradation by combined sonolysis and ozonation. Dyes Pigments, 49: 145-153. DOI: 10.1016/S0143-7208(01)00019-5

Ji, X., X. Song, J. Li, Y. Bai and W. Yang et al., 2007. Size control of gold nanocrystals in citrate reduction: The third role of citrate. J. Am. Chemical Society, 129: 13939-13948. DOI: $10.1021 / \mathrm{ja} 074447 \mathrm{k}$

Krumov, N., I. Perner-Nochta, S. Oder, V. Gotcheva and A. Angelov et al., 2009. Production of inorganic nanoparticles by microorganisms. Chemical Eng. Technology, 32: 1026-1035.

DOI: $10.1002 /$ ceat.200900046

$\mathrm{Li}, \mathrm{J}$. and $\mathrm{Z}$. Xu, 2010. Environmental friendly automatic Line for recovering metal from waste printed circuit boards. Environ. Sci. Technol., 44: 1418-1423. DOI: $10.1021 / \mathrm{es} 903242 \mathrm{t}$

Li, J., H. Lu, J. Guo, Z. Xu and Y. Zhou, 2007. Recycle technology for recovering resources and products from waste printed circuit boards. Environ. Sci. Technol., 41: 1995-2000. DOI: 10.1021/es0618245

Li, P., Y. Song, S. Wang, Z. Tao and S. Yu et al., 2015. Enhanced decolorization of methyl orange using zero-valent copper nanoparticles under assistance of hydrodynamic cavitation. Ultrasonics Sonochemistry, 22: 132-138.

DOI: 10.1016/j.ultsonch.2014.05.025

Macdonald, I.D.G. and W.E. Smith, 1996. Orientation of cytochrome $\mathrm{c}$ adsorbed on a citrate-reduced silver colloid surface. Langmuir, 12: 706-713. DOI: $10.1021 /$ la950256w

Majumder, D.R., 2013. Waste to health: Bioleaching of nanoparticles from e-waste and their medical applications. Indian J. Applied Res., 3: 277-288. DOI: $10.15373 / 2249555 \mathrm{X} / \mathrm{FEB} 2013 / 94$

Mallikarjuna, K., G. Narasimha, G.R. Dillip, B. Praveen and B. Shreedhar et al., 2011. Green synthesis of silver nanoparticles using Ocimum leaf extract and their characterization. Digest J. Nanomaterials nd Biostructures, 6: 181-186.

Mishra, D. and Y.H. Rhee, 2010. Current research trends of microbiological leaching for metal recovery from industrial wastes. Curr. Res. Technol. Educ. Topics Appl. Microbiol. Microb. Biotechnol., 2: 1289-1292.
Patra, J.K. and K.H. Baek, 2014. Green nanobiotechnology: factors affecting synthesis and characterization techniques. J. Nanomaterials, 2014: 1-12. DOI: $10.1155 / 2014 / 417305$

Petrov, T., I. Markova-Deneva, O. Chauvet, R. Nikolov and I. Denev, 2012. SEM And FT-IR Spectroscopy study of $\mathrm{Cu}, \mathrm{Sn}$ and $\mathrm{Cu}-\mathrm{Sn}$ nanoparticles. J. University Chemical Technology Metallurgy, 47: 197-206.

Pradhan, J.K. and S. Kumar, 2012. Metals bioleaching from electronic waste by Chromobacterium violaceum and Pseudomonads sp. Waste Management Res., 30: 1151-1159.

DOI: $10.1177 / 0734242 X 12437565$

Ramanathan, R., M.R. Field, A.P. O'Mullane, P.M. Smooker and S.K. Bhargava et al., 2013. Aqueous phase synthesis of copper nanoparticles: A link between heavy metal resistance and nanoparticle synthesis ability in bacterial systems. Nanoscale, 5: 2300-2306. DOI: 10.1039/C2NR32887A

Ruan, J., J. Li and Z. Xu, 2013. Improvements of the recovery line of waste toner cartridges on environmental and safety performances. Environ. Sci. Technol., 47: 6457-6462. DOI: $10.1021 / \mathrm{es} 305311 \mathrm{k}$

Rege, A.A., R.Y. Ambaye and R.A. Deshmukh, 2010. In-vitro testing of anti-HIV activity of some medicinal plants. Indian Journal Natural Products Resources, 1: 193-199.

Sampath, M., R. Vijayan, E. Tamilarasu, A. Tamilselvan and B. Sengottuvelan, 2014. Green synthesis of novel jasmine bud-shaped copper nanoparticles. J. Nanotechnology, 2014: 1-7. DOI: $10.1155 / 2014 / 626523$

Sharma, N., P. Madan and S. Lin, 2016. Effect of process and formulation variables on the preparation of parenteral paclitaxel-loaded biodegradable polymeric nanoparticles: A co-surfactant study. Asian J. Pharmaceutical Sci., 11: 404-416. DOI: 10.1016/j.ajps.2015.09.004

Sheng, P.P. and T.H. Etsell, 2007. Recovery of gold from computer circuit board scrap using aqua regia. Waste Management Res., 25: 380-383. DOI: $10.1177 / 0734242$ X07076946

Simon, J.E., M.R. Morales, W.B. Phippen, R.F. Vieira and Z. Hao, 1999. Basil: A source of aroma compounds and a popular culinary and ornamental herb. Perspectives New Crops New Uses, pp: 499-505.

Singhal, G., R. Bhavesh, K. Kasariya, A.R. Sharma and R.P. Singh, 2011. Biosynthesis of silver nanoparticles using Ocimum sanctum (Tulsi) leaf extract and screening its antimicrobial activity. J. Nanoparticle Res., 13: 2981-2988. DOI: $10.1007 / \mathrm{s} 11051-010-0193-y$ 
Soundarrajan, C., A. Sankari, P. Dhandapani, S. Maruthamuthu and S. Ravichandran et al., 2012. Rapid biological synthesis of platinum nanoparticles using Ocimum sanctum for water electrolysis applications. Bioprocess Biosystems Engineering, 35: 827-833. DOI: 10.1007/s00449-011-0666-0

Subhankari, I. and P.L. Nayak, 2013. Synthesis of copper nanoparticles using Syzygium aromaticum (cloves) aqueous extract by using green chemistry. World J. Nano Sci. Technol., 2: 14-17.

Varshney, R., S. Bhadauria, M.S. Gaur and R. Pasricha, 2011. Copper nanoparticles synthesis from electroplating industry effluent. Nano. Biomed. Eng., 3: 115-119. DOI: 10.5101/nbe.v3i2.p115-119

Willner, J.O.A.N.N.A. and A. Fornalczyk, 2013. Extraction of metals from electronic waste by bacterial leaching. Environ. Protection Eng., 39: 197-208.

Xiang, Y., P. Wu, N. Zhu, T. Zhang and W. Liu et al., 2010. Bioleaching of copper from waste printed circuit boards by bacterial consortium enriched from acid mine drainage. J. Hazardous Materials, 184: 812-818. DOI: 10.1016/j.jhazmat.2010.08.113
Xiong, J., Y. Wang, Q. Xue and X. Wu, 2011. Synthesis of highly stable dispersions of nanosized copper particles using L-ascorbic acid. Green Chemistry, 13: 900-904. DOI: 10.1039/c0gc00772b

Zare, E., S. Pourseyedi, M. Khatami and E. Darezereshki, 2017. Simple biosynthesis of zinc oxide nanoparticles sing nature's source and it's in vitro bio-activity. J. Molecular Structure, 1146: 96-103. DOI: 10.1016/j.molstruc.2017.05.118

Zhang, H.X., U. Siegert, R. Liu and W.B. Cai, 2009. Facile fabrication of ultrafine copper nanoparticles in organic solvent. Nanoscale Res. Lett., 4: 705-708. DOI: $10.1007 / \mathrm{s} 11671-009-9301-2$ 